\author{
Mayuki Aibiki
}

\section{Bispectral index and suppression ratio during hypothermia after cardiac arrest}

Accepted: 29 May 2011

Published online: 18 June 2011

(C) Copyright jointly held by Springer and ESICM 2011

An author's reply to this comment is available at: doi:

10.1007/s00134-011-2284-3.

Dear Editor,

I read with interest the paper written by Dr. Seder et al. [1].

Neurological outcome is challenging to predict in unconscious postcardiac arrest syndrome (PCAS) patients especially during therapeutic hypothermia. Dr. Seder's paper reported that a low bispectral index (BIS) value and a high suppression ratio (SR) could predict poor outcome even in the very early phase (mean time of $280 \mathrm{~min}$ ) after the resumption of spontaneous circulation (ROSC) in PCAS patients [1]. We have examined serial data of BIS and SR in PCAS patients for determining the neurological outcome under the continuous administration of muscle relaxant from soon after ROSC [2]. In these series, we had a case of very low BIS (near zero) and high SR (around 90) soon after ROSC, which were followed by a gradual increase in BIS values and a decrease in SRs within $12 \mathrm{~h}$ after admission. Thereafter, these changes were so apparent that BIS values elevated to higher levels than those of SRs $40 \mathrm{~h}$ after admission. This patient eventually recovered to cerebral performance category (CPC) level 2.

Dr. Seder's group obtained intermittent data of BIS and SR after bolus injection of neuromuscular blockade and concluded that a BIS value less than 22 (sensitivity 0.86 and specificity 0.94 ) and SR more than 48 (sensitivity 0.84 and specificity 0.93 ) could predict poor outcome of CPC $3-5$ even in the very early phase after ROSC. However, such data obviously included false positive cases.
In this letter, we emphasize a potential failure to predict neurological outcome when using intermittent sampling of BIS value in unconscious PCAS patients treated with hypothermia in the very early phase as Dr. Seder's group indicated.

\section{References}

1. Seder DB, Fraser GL, Robbins T, Libby L, Riker RR (2010) The bispectral index and suppression ratio are very early predictors of neurological outcome during therapeutic hypothermia after cardiac arrest. Intensive Care Med 36:281-288. doi: 10.1007/s00134-009-1691-1

2. Aibiki M, Kikuchi S, Umakoshi K, Ohshita M, Matsumoto H, Ohtsubo S, Nishiyama T (2010) Neurological outcome for unconscious post-cardiac arrest syndrome patients can be predicted by bispectral index. Shock 33:62S

\section{Aibiki (四)}

Division of Emergency Medicine,

Ehime University Hospital,

Shitsukawa 454, Tohon,

Ehime 791-0295, Japan

e-mail: aibiki@m.ehime-u.ac.jp

Tel.: +81-89-9605722

Fax: +81-89-9605714 